\title{
Erratum to: The role of gender and labour status in immunosenescence of 65+ Polish population
}

\author{
Magdalena Dudkowska - Dorota Janiszewska - Anna Karpa - Katarzyna Broczek • \\ Michal Dabrowski · Ewa Sikora
}

Published online: 7 July 2017

(C) Springer Science+Business Media B.V. 2017

\section{Erratum to: Biogerontology DOI 10.1007/s10522-017-9702-z}

In the original publication, the affiliations of fourth and fifth authors have been incorrectly published.

The correct affiliations are given below:

K. Broczek

Department of Geriatrics, Medical University of Warsaw, Oczki Str. 4, 02-007 Warsaw, Poland

e-mail:kbroczek@gmail.com
The online version of the original article can be found under doi:10.1007/s10522-017-9702-z.

\section{Dabrowski}

Laboratory of Bioinformatics, Nencki Institute of Experimental Biology of Polish Academy of Sciences, Pasteur Str. 3, 02-093 Warsaw, Poland e-mail: m.dabrowski@nencki.gov.pl

\author{
M. Dudkowska $(\bowtie) \cdot$ D. Janiszewska . \\ A. Karpa · E. Sikora \\ Laboratory of Molecular Bases of Aging, Department of \\ Biochemistry, Nencki Institute of Experimental Biology \\ of Polish Academy of Sciences, Pasteur Str. 3, \\ 02-093 Warsaw, Poland \\ e-mail: m.dudkowska@nencki.gov.pl \\ D. Janiszewska \\ e-mail: d.janiszewska@nencki.gov.p
}
A. Karpa
e-mail: a.karpa@nencki.gov.pl
E. Sikora
e-mail: e.sikora@nencki.gov.pl

K. Broczek

Department of Geriatrics, Medical University of Warsaw,

Oczki Str. 4, 02-007 Warsaw, Poland

e-mail: kbroczek@gmail.com

M. Dabrowski

Laboratory of Bioinformatics, Nencki Institute of

Experimental Biology of Polish Academy of Sciences,

Pasteur Str. 3, 02-093 Warsaw, Poland

e-mail: m.dabrowski@nencki.gov.pl 